\section{0 b USING PRECISION TEACHING AS A FRAMEWORK TO SUPPORT SIMULATION BASED EDUCATION}

D Byrne. Irish Centre for Applied Patient Safety and Simulation at NUI Galway and University Hospital Galway, Galway, Ireland

\subsection{6/oemed-2018-ICOHabstracts.274}

Traditional approaches to skills training are insufficient for developing competency in a safe and ethical manner. There is a need for the evaluation of novel skills training approaches. Simulation Based Education (SBE) has emerged as a popular solution allowing learners to perform procedures, make mistakes and receive feedback in an environment that replicates real life. Many institutions are investing heavily in the purchasing of simulators. However, there is a lack of consensus regarding best practice for employing simulation technology to teach skills and the frequent lack of consideration given to educational framework, or instructional design, may be criticised. Behavioural fluency has been described as 'that combination of accuracy plus speed of responding that enables competent individuals to function efficiently and effectively in their natural environment.' Behaviour that is learnt to fluency is Retained for longer periods of time, individuals can Endure performing the skill for longer durations, can Adapt the behaviour learnt by performing it as part of a new, more complex, compound behaviour, can Perform the skill at a rate that makes it functional and their performance is Stable regardless of distraction (REAPS). Precision teaching (PT) has been defined as 'a system for defining instructional targets, monitoring daily performance, and organising and presenting performance data in a uniform manner to facilitate timely and effective instructional decisions. The crucial difference between other educational interventions and interventions including PT is the focus on the speed of performance, as the 'flow' of behaviour is the hallmark of fluency and high accuracy alone is insufficient for producing the outcomes of behaviour fluency (ie, REAPS). This presentation describes our experience and research in using PT to teach technical skills in a simulated environment and describes an effect of training in the lab, in practice and on patient outcomes.

\section{C ANALYSING OUTCOMES: DECIDING WHAT TO LEARN IN POSTGRADUATE MEDICAL TRAINING}

AJ Smith. Royal College of Physicians of Ireland, Dublin, Ireland

\subsection{6/oemed-2018-ICOHabstracts.275}

In 2017 RCPI designed a methodology for transforming traditional post graduate training curricula to outcome based curricula. This model was applied to, and refined with a pilot. Background research for the project was based on education theory but the methodology itself takes the approach of a job analysis. An overview of how job analysis is performed will be discussed together with its links to competencies and outcome-based education.

\section{OCCUPATIONAL HEALTH GUIDELINES IN NORWAY}

MD Bugge*. STAMI, National Institute of Occupational Health, Norway
Introduction Quality improvement is a continuous challenge in medical work.

Methods In order to promote better quality in all medical disciplines, the Norwegian Medical Association in the late 1990ies encouraged all medical specialties to consider which topics could fit for standardised procedures. The Norwegian Association of Occupational Physicians decided to ask experienced occupational physicians to develop guidelines in their respective fields of work. These guidelines were posted on the Internet, and were thus made widely available for free.

Results By 2017, about 130 guidelines are published. The guidelines are continuously updated and revised, and new guidelines are developed when needed. After more than 15 years on the Internet, they are well known among Norwegian occupational physicians. In an informal survey among around 100 occupational physicians we experienced that all participants knew the guidelines, about 50\% consider them as part of their daily 'toolkit', and new, inexperienced, colleagues found a good basis for their work in these guidelines.

Conclusion The idea and the structure of the internet page will be presented in a poster, and the web page demonstrated on a laptop. We hope that they will be an inspiration for other associations of occupational health personnel.

\section{NETWORM PROJECT, ROMANIAN EXPERIENCE}

Elena-Ana Păuncu*, Florina Georgeta Popescu, Cristina Livia Borcan. University of Medicine and Pharmacy 'Victor Babes' (UMFVBT), Timisoara, Romania

\subsection{6/oemed-2018-ICOHabstracts.277}

Introduction Training undergraduate students in occupational medicine is a challenge for university teachers. To choose an 'interesting' curriculum, to present problems in an attractive way, to maintain students' interest are some aspects that we must take in consideration. In Timisoara we apply blended learning for our students.

Methods NetWoRM ('Net-based Training for Work-Related Medicine') is an international project for remote education in occupational medicine, which was initiated by the Institute of Occupational and Environmental Medicine of the Ludwig Maximilian University in Munich.

It was implemented in Romania, Timisoara, Medicine University since 2007. Virtual patients from Casus platform were available for Timisoara students in Romanian and English language. Classroom participation is encouraged too, considering it can improve student achievement.

Results Students had to solve voluntary ten occupational medicine cases. These were typical cases: Running nose and breathlessness fits, Stomach cramps and anaemia, The Flight attendant, Forestry worker with white fingers, Needle stick injury, They who search will find, Patient with chronic dyspnoea needs your help!, Bright like the sun, Work accident due by alcohol, Workplace Survey. In the period of 2014-2017 1255 users worked in 11532 sessions (11 325 were finished). There were 9.04 sessions per student, with $29.27 \mathrm{~min}$ average time spent to solve one case.

Conclusion Teaching with virtual patient was effective. The virtual cases are well accepted and capture the interest of students. The positive experience of using NetWoRM in UMFVBT for more than 10 years is a good reason to continue. 
1578 THE GLOBALLY HARMONISED SYSTEM CHEMICALS IMPLEMENTATION IN ORDER TO STABLISH HEALTH AND ENVIRONMENTAL RISKS (SUCCESSFUL INDUSTRY CASE)

AL Fajardo Montiel, HU Ramirez Sánchez, ARMeulenert Peña. Universidad de Guadalajara, Guadalajara Jalisco México

\subsection{6/oemed-2018-ICOHabstracts.278}

Introduction The GHS (The Globally Harmonised System of Classification and Labelling of Chemicals) is a specially system for standardising and harmonising the classification and labelling of chemicals at the industry. The main objective is to define health, physical and environmental hazards of chemicals. Due there is no international implementation procedure for the GHS, existing systems should develop transition strategies in order to fulfil the

GHS requirements, and be sure to fulfil new ISO 14001:2015 requirements

Methods According with the Mexican standard NMX-R-019SCFI-2011, the classification of chemicals or mixtures incorporates this three steps: Identifying relevant data on the hazards of the substance or mixture, Analysis to identify hazards associated with the substance or mixture and stablish the corresponding hazard communication.

The label system is designed including: Warning words, danger indication, precautionary statements and pictograms, supplier identification and Material safety data sheet information.

After the organisation get this documents, starts the basic elements that include: aquatic toxicity, potential or actual bioaccumulation; degradation (biotic or abiotic) of organic chemicals; and chronic aquatic toxicity. The health hazards is determinate according ONU Purple book (part III).

The final stage include to design a specific procedure al the industry in order to determinate health and environmental risk with a complete methodology to fulfil ISO 14001:2015 standard.

Results One of the main issues is to be sure that the Material safety data sheet provide complete information on a chemical, transportation and emergency actions, with the complete information an according ISO 14001:2015 standard the industry get an specific procedure to integrate GHS requirements with an update process, and then be ready to implement this at Mexico Region,

Conclusion This is the first time that an international standard with a local legislation is integrated and develop a methodology that is effective at different buildings in the same company

\section{EDUCATION ABOUT HEALTH PROTECTION OF HEALTHCARE WORKERS RELATED TO HAZARDOUS DRUGS IN CROATIAN HOSPITALS}

${ }^{1}$ Bojana Knezevic, ${ }^{2}$ Ivana Kerner. 'University Hospital Centre Zagreb, Zagreb, Croatia; ${ }^{2}$ Health Institution for Occupational Health Bonifarm, Zagreb, Croatia

\subsection{6/oemed-2018-ICOHabstracts.279}

Introduction Hazardous drugs have one or more following characteristics: carcinogenicity, teratogenicity, reproductive toxicity, organ toxicity at law doses and genotoxicity. Health care workers who prepare or administer the hazardous drugs (e.g. cancer chemotherapy drugs) or who work in places where these drugs are used may be exposed to these agents in the workplace. In Croatia there are no legal regulatory acts and there are no national guidelines to define how to protect healthcare workers who are at risk of exposure to cytotoxic drugs.

Aim of this case report is to show good practice of health protection of healthcare workers in University Hospital Centre (UHC) Zagreb.

Methods Training course was organised by the UHC for all healthcare workers who might be exposed to cancer chemotherapy drugs. Health assessments of all those workers were provided by occupational health physician who have contracted with the employer and provide the health surveillance of workers who are in the risk for health and safety.

Result There were 5 training courses during the period of two years (2015-2017.) Out of 250 workers, 200 participated in the training course. All workers who were in the risk of exposure to cytotoxic drugs have to visited occupational health institute for health assessment (prior to exposure and at regular intervals thereafter). All workers, who were examined for that workplace, had fitness for work. Workers were no suffering ill-health due to possible exposure.

Conclusion UHC organised the training course to raise awareness about the hazardous drugs in hospital and improve knowledge and safety at work of healthcare workers. The obligation of the employer is to assess the hazards and dangerous at the workplace and manage the risk of exposure to carcinogens or mutagens. This process shall be renewed regularly.

\section{USE OF A RISK ASSESSMENT TO ASSIST FARMERS WITH OSH MANAGEMENT IN IRELAND}

1J McNamara*, ${ }^{2} \mathrm{P}$ Griffin, ${ }^{3} \mathrm{~J}$ Phelan, ${ }^{3} \mathrm{~J}$ Kinsella. ${ }^{1}$ Teagasc- Agriculture and Food Development Authority, Kildalton, Co. Kilkenny, Ireland; 'Health and Safety Authority, Dublin 1, Ireland; ${ }^{3}$ School of Agriculture, University College Dublin, Ireland

\subsection{6/oemed-2018-ICOHabstracts.280}

Introduction In Ireland, persons at work, including selfemployed farmers, are subject to the regulatory framework of the Safety, Health and Welfare at Work Act, 2005. This legislation requires the person in control of a workplace to prepare and implement a written workplace specific OSH management programme, referred to as a 'Safety Statement'. The legislation permits workplaces employing three or less workers to complete a Risk Assessment (RA) prepared under a statutory Code of Practice (COP) as an alternative to completing a Safety Statement. Following enactment of the 2005 legislation, the Irish Health and Safety Authority and Teagasc - the Irish Agriculture and Food Development Authority formed an alliance to: prepare the COP and RA; assist farmers to implement the RA, with or without half-day training, and to evaluate RA utility. This paper outlines some findings of evaluations related to RA completion and control implementation.

Methods RA documents from farmers $(n=335$, with training; $\mathrm{n}=135$, without training) were obtained and controls specified for action assessed. Farm audits $(n=94)$ were undertaken for farms where a RA document was obtained to assess implementation of RA controls specified and farm OSH standards. Data was analysed using SPSS.

Results The evaluation found that farmers specified, on average, 3 controls (2.94\% of controls in RA) for implementation 